\title{
UMA ÉTICA PARA OS NOVOS DESDOBRAMENTOS DA REFORMA PSIQUIÁTRICA
}

Oswaldo França Neto

Psicanalista, professor adjunto do Programa de PósRESUMO: Fazendo uso de elaborações de Giorgio Agamben e Alain graduação strito sensu do Departamento de Psicologia da UFMG. Badiou, e tendo como pano de fundo a teoria lacaniana, este texto propõe que a Reforma Psiquiátrica teria entrado em uma segunda etapa, sendo necessário ressituarmos o que seria uma ética que contemplasse seus novos desdobramentos.

Palavras-chave: Reforma Psiquiátrica, responsabilização, ética, via "subtrativa".

ABSTRACT: Ethics for the new development in psychiatric reform. Through a study of the works of Giorgio Agamben and Alain Badiou, and based on the Lacanian theory, this paper proposes that the Psychiatric Reform has entered into a second phase, therefore requiring a new look at the standard of ethics in light of these developments.

Keywords: Psychiatric Reform, responsibilization, ethics, "subtractive" way.

Tá cerca de 30 anos vem tomando corpo no Brasil um movimento social que milita pela desinstitucionalização do paciente psiquiátrico. Esse movimento não é criação nossa, tendo raízes em propostas similares que, em graus variados, provocaram mudanças não negligenciáveis na maneira de se encarar a questão da saúde mental em outros países. No nosso país aprendemos a chamar esse movimento de Reforma Psiquiátrica.

Mas do que se trata realmente? Qual a lógica que norteia sua direção? Ele permanece o mesmo desde o início, ou já podemos identificar alterações nos seus objetivos imediatos? É possível propor uma ética que, concernente à Reforma, norteasse sua ação ao longo de um processo que, talvez, esteja em transformação? 
Louis Althusser, em sua última obra, póstuma, autobiográfica (ALTHUSSER, 1992), escrita durante internação em um manicômio após haver assassinado sua esposa, não se defende da acusação de crime. Ele não nega o ato cometido, nem que mereceria ser colocado a priori em liberdade. Ele clama pela possibilidade de ser julgado. A pior coisa que teria lhe acontecido foi ter sido considerado louco, e com isso perdido o direito de se defender. Ao tentar preservá-lo de uma exposição pública internando-o em um hospital psiquiátrico, as pessoas que lhe eram próximas condenaram-no ao mutismo. Tornando-se inimputável, passou a não mais ser reconhecido como sujeito.

A questão que se coloca neste episódio não é a capacidade de um doente mental de discernir o certo do errado, ou as dificuldades para se estabelecer uma pena para crime cometido em tais circunstâncias. O que está em jogo é a interdição promovida pela sociedade, impedindo que alguém, até então um cidadão em gozo de seus direitos e deveres, possa se fazer reconhecer como tal e continuar a se responsabilizar por seus atos. Se, seguindo Freud em "Totem e tabu” (FREUD, 1912[1912-13]/1974), é o ato que nos constitui como sujeito na civilização, ao não-reconhecermos em determinado indivíduo a sua capacidade em responder por seus atos, são estes últimos que são colocados em causa, comprometendo sua eficácia em fazer existir um sujeito. Desresponsabilizar alguém é condená-lo à inexistência.

Discussões referentes à responsabilidade legal têm sido recorrentes nos últimos tempos, colocando-se cada vez mais em questão quais seriam os benefícios para a sociedade continuar a fazer uso com tal frequência da noção de inimputabilidade. Como nos lembra Célio Garcia, na França há, hoje, uma clara tendência em considerar cada vez mais as perturbações psiquiátricas como agravantes, e não atenuantes, as prisões tornando-se sucedâneas do hospital psiquiátrico, este último oficialmente em vias de extinção (GARCIA, 2002).

Ao se falar em ética na Reforma, poderíamos propor que ela teria, como perspectiva geral, algo em torno de uma responsabilização do louco, implicandoo na existência enquanto sujeito. Nesse sentido, o primeiro grande passo foi a derrubada dos muros dos nosocômios, visando com isso criar as condições para a inscrição da loucura na pólis. Mas a questão é mais complexa. Para se atingir esse objetivo, tudo indica que não podemos nos restringir a essa primeira etapa. Uma desinstitucionalização progressiva, apesar de necessária, não tem se mostrado suficiente para garantir uma real mudança no status jurídico do "louco". Sua responsabilização jurídica não é simples, pois este se encontra em uma imprecisa zona de indiscernibilidade, na qual os limites legais exigem contínua reformulação.

Pode-se dizer que a loucura, ao tentar absorver-se pelo Direito, coloca-o em situação delicada, de suspensão, em que sua ação exige reposicionamentos difi- 
cilmente universalizáveis. Poderíamos inclusive aventar, em vista das discussões que têm cercado esse tema, que talvez seja a questão da responsabilidade legal daqueles até então considerados inimputáveis o território mais propenso a nos propiciar elementos para repensarmos uma localização possível para o sujeito nos tempos atuais.

Os manicômios já esgotaram sua potencialidade em mobilizar nossas reflexões. Tornou-se necessário destituí-los do lugar de referência para tratamento dos “insanos”, para que pudessem voltar a adquirir a potência de colocar em questão nossas universalidades. Hoje, talvez seja primordialmente nos impasses causados pela inscrição jurídica e social dos loucos, dos menores infratores, dos imigrantes ilegais e de todos aqueles que colocam em xeque a universalidade instituída, o local por excelência onde novas subjetividades possam vir a ser pensadas.

\section{A MODERNIDADE E O CAPITALISMO}

Segundo Agamben, o evento decisivo da modernidade se deu já a partir da Primeira Guerra Mundial (AGAMBEN, 2004, p.44), com “o ingresso da zoé na esfera da pólis, a politização da vida nua como tal” (AGAMBEN, 2004, p.12). ${ }^{1}$ Trata-se, aqui, do que Agamben, seguindo Foucault, chama de biopolítica. Nesta, as pessoas são reduzidas a sua pura existência biológica — zoé, ou vida natural —, submetidas a um Outro totalitário. E a biopolítica, apesar de vir a se explicitar de tal forma apenas neste momento, tem raízes antigas, provavelmente tão antigas quanto a história do Ocidente.

Agamben introduz o termo "estado de exceção” para falar dessa biopolítica em ação. O estado de exceção é uma “"zona de indiferença entre externo e interno, caos e situação normal” (AGAMBEN, 2004, p.27). Nele, o poder soberano encontra-

\footnotetext{
${ }^{1}$ Vida nua (zoé) é a existência despojada de todo valor político, de todo valor cidadão. Para os gregos designava o simples fato de viver, comum a todos os seres vivos (animais, homens ou deuses), distinta da vida qualificada (bios), que indicava a forma ou maneira de viver própria a um indivíduo ou grupo. Nas palavras de Agamben, vida nua seria a "vida matável e insacrificável do homo sacer" (AGAMBEM, 2004, p.16).

Homo sacer: "obscura figura do direito romano arcaico, na qual a vida humana é incluída no ordenamento unicamente sob a forma de sua exclusão (ou seja, de sua absoluta matabilidade)" (AGAMBEM, 2004, p.16). O homo sacer seria o homem cuja vida teria sido consagrada a Júpiter, portanto separada do resto das vidas da pólis, mas que teria sobrevivido do rito sacrifical da consagração. Por estar em situação de dupla exclusão (dos deuses e dos homens), se de um lado ele não mais poderia ser sacrificado num sentido religioso ou ritual, seu assassinato também não mais representaria qualquer delito. Estando fora tanto do direito humano (por ser sagrado) quanto do direito divino (por ser matável de maneira não sacrifical), ele habitaria uma zona de indistinção entre a vida humana e a morte consagrada, fora do espaço jurídico e ao mesmo tempo enquadrado por ele, sendo a representação perfeita de uma vida nua, que não merece ser vivida. Essa figura, para Agamben, teria reaparecido no século XX com os campos de concentração e de extermínio, e seria a metáfora paradigmática do homem moderno.
} 
se em situação de exceção, posto que tanto está fora quanto dentro da lei, existindo como incorporação da lei absoluta ("O estado de exceção é um espaço anômico, onde o que está em jogo é uma força de lei sem lei”, AGAMBEN, 2003, p.3.) Para Agamben, o estado de exceção é a base formal sobre a qual se funda a modernidade. Ele é, a rigor, ilocalizável, difundindo-se partout, não sendo apreensível em parte alguma. "Quando”, continua o filósofo italiano, “o nosso tempo procurou dar uma localização visível permanente a este ilocalizável, o resultado foi o campo de concentração” (AGAMBEN, 2004, p.27). Os campos de extermínio nazista seriam, assim, a forma paradigmática da localização deste ilocalizável que é o estado de exceção.

Sob essa ótica, entender a lógica dos campos de extermínio é entender a lógica que subsiste na base da sociedade moderna. Para se chegar até ele, a Alemanha de Hitler promoveu um progressivo despojamento do estatuto jurídico do judeu, até a completa perda de sua cidadania. Nos campos, são indivíduos reduzidos à mera existência biológica. Eles se encontram à parte da sociedade, fora da vida. Matá-los não é crime, assim como seu sacrifício não carreia qualquer significado sagrado ou profano. Trazendo para os tempos atuais, a eles corresponderiam, por exemplo, os campos de refugiados e imigrantes ilegais que se espalham pelos países do primeiro mundo e pelas zonas de conflito, depósitos de pessoas que se encontram em situação de suspensão, vida nua sitiada à parte pelo sistema. Não sendo reconhecidas como cidadãs, é como se sua existência física tivesse sido separada de seu status jurídico.

Agamben, no entanto, faz questão de frisar que, nos campos de extermínio e nos manicômios, não se trata exatamente da mesma coisa. Há ali uma diferença. O campo não é um simples espaço de reclusão, como o seriam os manicômios. Nos campos, "o nexo entre localização e ordenamento é definitivamente rompido” (AGAMBEN, 2004, p.27), o que ainda não teria ocorrido nos hospitais psiquiátricos. Estes ainda estariam dentro do ordenamento jurídico. Mesmo assim, não nos parece inoportuno utilizar um para entender o outro. Se os campos são a localização do ilocalizável, com os manicômios segregou-se da pólis uma das coisas que poderia veicular, ou corporificar, esse excesso ilocalizável.

Com os manicômios, tem-se a exclusão do ilocalizável, ou, em outros termos, a exclusão da exclusão. A instituição manicomial seria uma das formas de nos protegermos da necessidade de nos defrontarmos com nosso próprio estado de exceção, escamoteando a crueza de sua aparição desnuda. Excluindo juridicamente a exclusão, o hospício insere de modo fictício o excesso no ordenamento legal. Se o excesso torna-se objeto de regulamentação, sua localização intramuros passa a se apresentar apenas como mera contenção, barrando o que nele poderia ter de subversivo para a sociedade. O movimento da Reforma se faz no sentido 
inverso. Ela visa à inclusão da exclusão, possibilitando que a loucura se recoloque na situação como excesso imanente.

Se os manicômios nunca chegaram de fato a funcionar como estados de exceção, eles foram, no entanto, uma das maneiras com que a pólis se utilizou para a segregação do ilocalizável. Ao fechar o excesso entre muros, este se viu fora da lógica do localizável/ilocalizável. A Reforma apresenta-se, então, como a viabilização de que a loucura volte a funcionar, de forma imanente, como resto inabsorvível.

Mas as resistências à Reforma são grandes. Com sua ação ela se opõe frontalmente ao sistema econômico subjacente ao funcionamento da sociedade moderna. Se a Reforma visa recolocar em cena o excesso, o capitalismo sustenta-se em uma extraordinária capacidade de retransformar em consumo tudo o que possa se constituir como resto. Nada escapa à sua engrenagem, e qualquer coisa que se apresente como estranha é rapidamente apreendida e consumida. O capitalismo capitaliza-se a si próprio, reencontrando saída para suas crises.

\section{A PROFANAÇÃO DA LOUCURA}

A Reforma Psiquiátrica, dessa forma, tem se apresentado como um problema para o sistema. Trata-se, nela, da inclusão de uma renitente exclusão, de uma improfanabilidade irredutível. Apesar do Iluminismo ver a loucura simplesmente como desrazão ou déficit, esta nunca se viu despojada por completo de certo caráter enigmático, mesmo sagrado, como se portadora de algo divino. O encarceramento do louco nos nosocômios não apenas nos protege de seus atos insanos, como nos resguarda de certa estranheza, mesmo religiosa, que a loucura nos provoca.

Para Agamben,

“podemos definir a religião como o que subtrai as coisas, os lugares, os animais ou as pessoas do uso comum para transferi-las para o seio de uma esfera separada. Não somente não há religião sem separação, mas toda separação contém ou conserva na sua posse um núcleo autenticamente religioso." (AGAMBEN, 2005, p.92 [tradução do autor])

E para profanar algo sacralizado é necessário o contágio, o contato. Profanar é "liberar a possibilidade de uma forma particular de negligência que ignora a separação ou, antes, que faz dela um uso particular" (AGAMBEN, 2005, p.93-4 [tradução do autor]). É por meio da profanação do que é sagrado/separado que se abrem as possibilidades para o aparecimento de novos usos, ou seja, segundo nossos termos, para que se coloque o surgimento de novas subjetivações. Mas para que tal ocorra algo de improfanável deve persistir. As operações de pro- 
fanação e seu inverso (passagem do profano ao sagrado), não se esgotam em si mesmas, já que “devem a cada vez dar conta de alguma coisa que é como um resíduo da dimensão profana em cada coisa consagrada, ou de um resto de sacralidade presente em cada objeto profanado" (AGAMBEN, 2005, p.97-8 [tradução do autor]).

O capitalismo, conforme já nos alertava Walter Benjamin, também pode ser entendido como uma forma de religião. Por meio de sua impressionante capacidade de transformar em consumo tudo o que se lhe apresenta, ele acaba por isolar-nos em um laico absoluto, separados de um sagrado doravante perdido:

“Em sua forma extrema, a religião capitalista realiza a forma pura da separação sem mais nada a separar. Uma profanação absoluta e sem o menor resíduo coincide doravante com uma consagração da mesma forma vazia e integral." (AGAMBEN, 2005, p.102 [tradução do autor])

Na engrenagem do consumo, onde não há restos, "todo uso torna-se duravelmente impossível” (AGAMBEN, 2005, p.103 [tradução do autor]), pois qualquer objeto que se apresente é de todo consumido, jogando-nos em uma infindável trilha de substituições. Como disse Jean XXIII (século XIII) em sua querela com os franciscanos, o consumo, que destrói necessariamente a coisa, não é nada mais do que a impossibilidade ou a negação do uso, já que o uso pressupõe que a substância da coisa reste intacta (salva rei substantia) (AGAMBEN, 2005, p.105). Na lógica do capitalismo, que funciona sob a égide da inexistência de restos, não existe nada que não seja totalmente profanável e consumível nas engrenagens do sistema.

Mas e a loucura, o que fazer com ela? Como lidar com um excesso que resiste, e insiste em se manter como tal? Ao incluirmos o louco na pólis - e isso a Reforma, ainda que de maneira precária, tem conseguido sustentar —, percebemos sua recusa em submeter-se à lógica do consumo. Apesar de aceitar apresentar-se, a loucura resiste como um resto irredutível, não se permitindo classificar como parte do universal. Algo de improfanável preserva o louco da assimilação completa, presentificando-se como um resto que faz ruído no funcionamento do sistema.

\section{A VIA SUBTRATIVA}

A questão que agora vem se colocando para a Reforma é como, a partir de um resto, produzir novas subjetividades, sem que essa produção se dê por meio de um puro confronto com o Outro, alternativa sempre difícil e extremamente dispendiosa para o paciente. Alain Badiou, em seu livro Le siècle (BADIOU, 2005), defende que o século XX forjou duas formas principais de abordagem do real 
visando à constituição de um sujeito. A primeira, mais ruidosa, seria a via destrutiva. Ela basear-se-ia em um processo depurativo levado às últimas consequências, sendo Stalin e o holocausto seus expoentes maiores.

O objetivo desta via seria preservar-se no puro ato disruptivo. Qualquer passo além implicaria um apagamento do sujeito, já que ela parte do princípio de que este só poderia existir no preciso instante do ato. Buscar-se-ia aqui a apreensão do ato em essência, instante apenso entre a estrutura precedente e aquela que está por vir. Na tentativa de manter-se subsumida na mais radical inapreensibilidade, porém sem ter como escapar da necessidade de preservar alguma constância que sirva de solo para seu funcionamento, esta via lança-se em uma produção incessante de restos e sua posterior destruição, como estratégia para repetidamente resgatar o momento exato da disrupção.

Dessa forma, e pelo menos sob esse aspecto em consonância com o capitalismo, também não haveria aqui espaço para a permanência de restos. A segunda forma proposta por Badiou, mais silenciosa, seria a via subtrativa. Nesta, apesar de não buscar o sujeito por meio da perenização no ato disruptivo, nem por isso se pautaria em um apaziguamento ou normalização do excesso.

No lugar da submissão ou do confronto destrutivo, e frente a uma sociedade que, nos últimos anos, em repúdio à devastadora via destrutiva, teria se voltado para um "niilismo passivo", "hostil a toda ação como a todo pensamento" (BADIOU, 2005, p.98 [tradução do autor]), a via subtrativa produziria um sujeito de forma imanente ao sistema, porém subtraindo-se a este por meio de uma diferença mínima. Seria uma ex-sistência do sujeito, que se sustentaria em disjunção ao simbólico universalizante de nossa contemporaneidade. No lugar da submissão, e sem buscar o confronto, viabilizar-se-ia ao excesso uma voz singular. Nesta via, o sujeito só é pensável a partir de um resto, de um traço, de uma diferença mínima. Sem ter como modus operante a pura e simples destruição, o sujeito aqui se escreve na subversão do sistema, por meio de uma lógica que lhe é estranha.

Uma singularidade, que poderíamos definir como sendo aquilo que se apresenta mas não se representa (apesar de se fazer presente, não se deixa predicar, mantendo-se assim inassimilável pela situação) (BADIOU, 1966, p.398), trata-se de "Um disjunto do universal” (GARCIA, 2002, p.313), ou do Um que não se deixa apreender em nenhuma das partes do Outro. Não propriamente por não aceitar fazer parte de classe alguma, mas, ao contrário, por não se deixar excluir por nenhuma delas. Ao colocar em questão a classificação, possibilitando-se em todas as classes e sem deixar aprisionar-se por qualquer que seja, a singularidade aponta para um universal que se dá de forma imanente, inapreensível pela lógica vigente. Lacan, em um dado momento, fala da "liberdade negativa de uma palavra [parole] que renunciou a se fazer reconhecer” na loucura, objetivando o 
“sujeito numa linguagem não dialética” [LACAN, 1953/1998, p.281]. Poderíamos entender aqui, nessa "liberdade negativa", não uma negação a toda e qualquer referência, mas uma negação ao aprisionamento pelo Outro. O psicótico se coloca em posição de recusa absoluta, podendo, por exemplo, isolar-se em seu mutismo, ou adotar uma posição irônica, pontuando a inconsistência das referências que lhe são apresentadas, o que o preservaria livre para uma referência imanente, não dialetizável, subtraída às classificações. Nessa liberdade negativa do psicótico não se trata de uma inexistência do sujeito, mas de uma ex-sistência, onde um sujeito se constitui no próprio ato de subtração, em disjunção com o Outro, inventando um território que lhe seja próprio, irredutível a qualquer classificação imposta por uma transcendência.

Voltando a Agamben, poderíamos talvez pensar em um dentro/fora, quando o que importa não é opor-se à lei que divide, mas re-dividir a própria divisão de forma que se reste como algo que não pode ser rechaçado por nenhuma das partes. Nas palavras dele, trata-se de dividir "a divisão ao invés de propor um princípio universal. E o que resta é o sujeito novo, mas indefinível, sempre em resto porque ele pode estar de todos os lados [...]" (AGAMBEN, 2000, p.7 [tradução do autor]). Talvez esteja aí uma opção para o louco: relocalizar-se, sem deixar absorver-se por parte alguma.

\section{O SEGUNDO MOMENTO DA REFORMA}

Podemos supor, então, que estamos em uma segunda etapa da Reforma. A fase de inclusão já a exercemos, ou a estamos exercendo. Apresentam-se agora novos desafios: o que fazer com a inclusão, com esse sintoma que criamos no seio da pólis? Como possibilitar a esse sintoma uma existência singular? Se o movimento inicial foi o forçamento de uma inclusão, o que fazer para que, existindo agora de forma imanente, possa o louco assegurar uma existência não assujeitada? Ou seja, se quisermos resguardar ao louco sua existência enquanto sujeito, devemos sim, incluí-lo, mas preservando-o como exclusão. Devemos criar as condições para um não-assujeitamento, viabilizando ao que não se adequa uma ex-sistência em relação ao sistema.

Porém, e temos aqui o que talvez seja nossa maior dificuldade, se a lógica do consumo não tolera restos, e se todo o seu funcionamento se organiza nessa direção, forçar a existência imanente de uma exclusão irredutível, implica em deixá-la em uma condição frágil, vulnerável, em risco permanente de aniquilamento. Situação esta — é importante lembrar — que não é exclusividade do louco, mas inerente a qualquer sujeito que queira sustentar-se como tal. Talvez na psicose essa discussão se coloque de forma mais pregnante, já que o preço a pagar pela não-ex-sistência do sujeito tende a ter, em geral, consequências mais catastróficas do que na neurose. 
A pertinência dessas questões torna-se ainda maior quando algumas dificuldades não aventadas no início do movimento da Reforma começam a aparecer. Com frequência os técnicos se veem investidos em medidas adaptativas, algumas vezes mesmo de cunho coercitivo, visando a uma inclusão mais suave do paciente. Essas atitudes não deixam de provocar discussões, logo identificadas pertinentemente por alguns como estando em contradição com os objetivos da Reforma.

Ao mesmo tempo, começamos a perceber que, em alguns momentos, o movimento do portador de sofrimento mental tem se preservado em uma resistência tenaz em relação àqueles responsáveis pelo seu tratamento. Tem-se a impressão de que, para os pacientes, os profissionais da Reforma são quase sempre vistos mais como obstáculos do que facilitadores, como se as tentativas de inclusão, apesar de aparentemente necessárias, se apresentassem para eles já como intervenção externa, e, portanto, como assujeitamento. Ao que parece, se aos agentes cabe a inclusão dos pacientes, nem por isso eles deixam de ser um dos Outros contra os quais estes deverão necessariamente resistir para assegurarem uma existência não assujeitada. Ou seja, se quisermos nos manter fiéis à Reforma, os profissionais devem ter em vista que sua ação deve implicar, desde o princípio, a construção de sua própria destituição. A eles é exigido o forçamento de uma inclusão, sabendo que será contra eles que os pacientes terão que se defrontar logo a seguir para que essa inclusão produza singularidades. É resistindo à inclusão, aparentemente em direção contrária ao que seria o objetivo inicial da Reforma, que os portadores de sofrimento mental poderão, agora dentro da pólis, preservarem-se inabsorvíveis e conquistarem assim sua existência. Aos profissionais cabe a incumbência de criar as condições para uma subjetivação, sabendo que o êxito dependerá, sob certo aspecto, de seu próprio fracasso. Trabalho ingrato para o técnico, mas que nem se compara àquele incumbido aos pacientes: como nos lembra outra vez Agamben, para escapar ao assujeitamento, “torna-se necessário por assim dizer preservar-se ao mesmo tempo nesse duplo movimento, dessubjetivação e subjetivação" (AGAMBEN, 2000, p.3 [tradução do autor]), como um desvio ou um resto entre esses dois processos.

Essa discussão sobre a prática, ou a ação, é o que nos autoriza a buscar uma ética para a Reforma. Estamos às voltas com uma prática, em que a ação envolvida exige o assentimento de uma destituição. É buscando libertar-se dos técnicos que os pacientes poderão resistir enquanto sujeitos. Com os profissionais e contra eles: tarefa impossível para os agentes de saúde, existência impossível para o "louco-sujeito". Trata-se, nas palavras de Agamben, de "uma prática, não um princípio”. Não cabe aqui o estabelecimento de princípios gerais, "salvo estar atento a não recair em um processo de re-subjetivação que seria ao mesmo tempo um assujeitamento, isto é, só ser um sujeito na medida de uma estratégia ou de uma tática” (AGAMBEN, 2000, p.3 [tradução do autor]). O trabalho dos 
técnicos deve recriar-se a cada momento, por meio do ultrapassamento de um fracasso inerente ao processo. O sucesso, aqui, significa fracasso, pois a única possibilidade de ex-sistência para o louco-sujeito baseia-se em uma reinscrição que frequentemente só pode viabilizar-se a partir do malogro do técnico.

A Reforma, assim, deve tomar o cuidado de não se colocar como objetivo fazer com que a sociedade inclua pura e simplesmente (consuma) o portador de sofrimento mental. Trata-se, como dissemos antes, de uma inclusão que deve preservar-se excluída, lembrando, porém, não ser a via do confronto e da destruição o melhor caminho para atingir esse objetivo. Ou seja, nem resignação, nem transgressão. Agamben propõe uma espécie de utilização/subversão da inscrição original:

“[...] fique na sua condição jurídica, em sua vocação social — porém transformando-as completamente por meio dessa forma do como não. Parece-me que a noção de uso, nesse sentido, é muito interessante: é uma prática da qual não podemos consignar o sujeito. Você permanece escravo, mas, desde que disso você faz uso, por meio do modo do como não, você não é mais escravo.” (AGAMBEN, 2000, p.4 [tradução do autor])

Trata-se do uso no lugar do consumo. É preservando-se como resto inabsorvível, não se deixando consumir, e fazendo uso de sua inscrição, que um sujeito pode escapar à alienação, separando-se do Outro sem comprometer a interseção (LACAN, 1964/1985). Lacan, ao trabalhar o caso Joyce (LACAN, 1975-76/2005), nos fala de algo similar. Ele reconhece, no escritor em questão, uma capacidade singular de gozar das palavras que o invadem, escapando dessa forma ao assujeitamento, sem se colocar, porém, em posição transgressiva. Joyce se deixa atravessar pelas palavras, e passa a brincar com elas. Lembremos também o filme documentário Estamira, de Marcos Prado, premiado em diversos festivais de cinema no Brasil — e no exterior — nos anos de 2004 e 2005. Nele é apresentado o percurso de uma portadora de sofrimento mental, psicótica, de 63 anos, que, conseguindo manter-se à margem da rotina dos dispositivos terapêuticos institucionais, não se deixa cronificar, construindo uma temporalidade própria a partir de sua trajetória de vida como catadora de lixo, por mais de 20 anos, no Aterro Metropolitano de Jardim Gramacho, no estado do Rio de Janeiro.

Estamira inventa seu território, do qual cuida, nele vive, dele retira seu sustento, e que se expande em algumas situações, indo além, bem longe, como na cena final, em que ela, em uma praia, esbraveja seus delírios. Vendo a construção de seu território, podemos pensar sua doença mental não a partir de uma essência mas de um acontecido, uma duração em sua trajetória pessoal.

A Reforma psiquiátrica e a Luta antimanicomial se inscrevem nesse capítulo. Há pouco tempo, como um passo a mais nesse processo, foi proposto que os plantões 
dos Cersam (Centros de Referência de Saúde Mental) da região metropolitana de Belo Horizonte (MG) passassem a ser exercidos por profissionais não médicos, cabendo ao psiquiatra a incumbência de manter-se de sobreaviso, em outro local, no caso eventual da necessidade de uma intervenção medicamentosa. Apesar das dificuldades e das resistências encontradas na implementação dessa proposta, tratava-se de uma tentativa a mais no sentido da desmedicalização do paciente, e de uma destituição não propriamente do médico, mas do técnico em geral.

Qual seria, então, uma ética para a Reforma? Acreditamos poder pensar em algo relativo ao espaço, à territorialização. Aprender a lidar, no nível local portanto não mais assujeitado a um universal transcendente - com um excesso que, apesar de inabsorvível, está lá para que se produza, com ele, alguma nova forma de uso. Caberia à Reforma, neste que poderíamos considerar como sendo seu segundo momento, sustentar a imanentização de um excesso, para que dele se viabilizem novas formas de subjetivação.

Recebido em 11/4/2007. Aprovado em 14/1/2008.

\section{REFERÊNCIAS}

ALTHUSEER, L. (1992) O futuro dura muito tempo. São Paulo: Companhia das Letras.

AGAMBEN, G. (2000) Une biopolitique mineure. Vacarme, n. 10. Disponível em: http://www.vacarme.eu.org. Acesso em: 2/5/2007. (2003) A zona morta da lei, Folha de S. Paulo (Caderno Mais!). São Paulo, 16/3/2003. UFMG. (2004) Homo Sacer — o poder soberano e a vida nua I. Belo Horizonte: (2005) Profanations. Paris: Poyot et Rivages.

BADIOU, A. (1996) O ser e o evento. Rio de Janeiro: Jorge Zahar Editor. (2005) Le siècle. Paris: Seuil.

FREUD, S. (1974) Edição standard brasileira das obras psicológicas completas de Sigmund Freud. Rio de Janeiro: Imago.

(1913 [1912-13]) “Totem e tabu”, v. XIII, p.13-191.

GARCIA, C. (2002) "Lacan e companhia”, in SAFATLE, V. (org.). Um limite tenso: Lacan entre a filosofia e a psicanálise. São Paulo: Unesp.

LACAN, J. (1964/1985) O seminário, Livro 11: os quatro conceitos fundamentais da psicanálise. Rio de Janeiro: Jorge Zahar Editor. (1953/1998) "Função e campo da fala e da linguagem em psicanálise”, in Escritos. Rio de Janeiro: Jorge Zahar Editor. (1975-76/2005) Le seminaire, Livre XXIII: le sinthome. Paris: Seuil.

Oswaldo França Neto

oswaldofranca@yahoo.com 